\title{
Análisis lingüístico-semiótico de las viñetas humorísticas sobre la covid-19
}

\author{
Linguistic-semiotic analysis of \\ humorous vignettes about covid-19
}

\author{
Edward Faustino Loayza-Maturrano \\ Universidad Nacional Agraria La Molina, Lima, Perú \\ edwloma@lamolina.edu.pe \\ ORCID: https://orcid.org/oooo-0oo2-1359-8414
}

\begin{abstract}
Resumen
El presente artículo propone una matriz de análisis para identificar los significados y las estrategias cognitivas que se utilizan al elaborar viñetas humorísticas. El objetivo del estudio es analizar lingüística y semióticamente las viñetas humorísticas de los principales diarios de la prensa de Lima Metropolitana en tiempo de pandemia. La metodología de la investigación es cualitativa del tipo análisis del discurso. Los resultados evidencian el empleo del tipo de humor negro, el uso frecuente de implicaturas y presuposiciones dentro de los fenómenos pragmáticos del discurso. También los resultados permitieron observar que las innovaciones lingüísticas de los globos y los recursos gráficos en las viñetas reflejan el proceso ejecutivo en el pensar-significar de las imágenes con intención humorística. La conclusión principal es que el análisis lingüístico-semiótico del discurso iconoglósico de las viñetas humorísticas permitió explicar la situación sociopolítica de la sociedad por la Covid-19 y la ideología de los diarios, así como determinar la evidencia de procesos cognitivos del lenguaje como la metáfora conceptual, la metonimia conceptual y la hipérbole conceptual. Se recomienda el empleo de la matriz de análisis en la interpretación de textos discontinuos.
\end{abstract}

Palabras clave: caricaturas periodísticas; formas de humor; pandemia Covid-19; lingüística cognitiva; análisis semiótico

\begin{abstract}
This article proposes an analysis matrix to identify the meanings and cognitive strategies used when developing humorous vignettes. The objective of the study is to linguistically and semiotically analyze the humorous cartoons of the main newspapers of the Metropolitan Lima press in times of pandemic. The research methodology is qualitative of the discourse analysis type. The results show the use of the type of black humor, the frequent use of implicatures and presuppositions within the pragmatic phenomena of discourse. The results also allowed us to observe that the linguistic innovations of the balloons and the graphic resources in the vignettes reflect the executive process in the thinking-meaning of the images with humorous intention. The main conclusion is that the linguistic-semiotic analysis of the iconoglossic discourse of the humorous cartoons made it possible to explain the sociopolitical situation of society due to Covid-19 and the ideology of the newspapers, as well as to determine the evidence of cognitive processes of language such as metaphor conceptual, conceptual metonymy and conceptual hyperbole. The use of the analysis matrix is recommended in the interpretation of discontinuous texts.
\end{abstract}

Keywords: journalistic cartoons forms of humor; Covid-19 pandemic; cognitive linguistics; semiotic analysis 


\section{Resumo}

Este artigo propõe uma matriz de análise para identificar os significados e as estratégias cognitivas utilizadas na elaboração de vinhetas humorísticas. O objectivo do estudo é analisar linguística e semiologicamente as vinhetas humorísticas dos principais jornais da imprensa metropolitana de Lima em tempos de pandemia. A metodologia de investigação é qualitativa, do tipo de análise do discurso. Os resultados mostram o uso do humor negro, o uso frequente de implicaturas e pressupostos no âmbito dos fenómenos pragmáticos do discurso. Os resultados também nos permitiram observar que as inovações linguísticas dos balões e dos recursos gráficos nas vinhetas reflectem o processo executivo no pensamento - significado das imagens com intenção humorística. A principal conclusão é que a análise lingüístico-semiótica do discurso iconoglósico dos desenhos animados humorísticos permitiu explicar a situação sociopolítica da sociedade por Covid-19 e a ideologia dos jornais, bem como determinar a evidência de tais processos cognitivos da linguagem como metáfora conceptual, metonímia conceptual e hipérbole conceptual. A utilização da matriz de análise na interpretação de textos descontínuos é recomendada.

Palavras chave: Caricaturas jornalísticas; formas de humor; pandemia do Covid-19; linguística cognitiva; análise semiótica

\section{Introducción}

En el siglo pasado surgieron varias teorías lingüísticas cuyas repercusiones superan el campo de la lingüística con alcances incluso en el arte y su crítica. Ferdinand de Saussure introdujo la idea de significante y significado que luego fue desarrollada por otros teóricos y críticos como Hjelmslev quien, por ejemplo, plantea la noción de plano del contenido y el plano de la expresión. Saussure (1916) define la semiótica como una disciplina que estudia la vida de los signos en la sociedad, denominándola con el término semiología (concepto derivado de la palabra griega semeion). La semiología mostraría qué constituyen los signos y qué leyes los gobiernan. De acuerdo con la perspectiva de Saussure (1916) una caricatura periodística o caricatura social al decodificar su mensaje implícito representa al lenguaje, pero de una forma desnaturalizada (Saussure, 1971).

Posteriormente, Charles Sanders Pierce en 1931 al renombrar esta disciplina autónoma que se ocupa del significante y significado con la denominación de semiótica determinó, a su vez, que la función de la semiótica es ayudarnos en la interpretación de la discursividad del comportamiento de las personas a través de los signos (Pierce, 1974). En ese sentido, Cathy Price \& Joseph Devlin (2003) en la investigación sobre la cognición y las palabras sostiene que la asimilación de la palabra-imagen tiene un gran significado en la interpretación de cualquier

$58 \quad$ Lengua y Sociedad. Revista de Lingüística Teórica y Aplicada 
discurso. En ese sentido, la interpretación de ambos discursos combinados (verbales y visuales) aporta nuevas dimensiones en el campo de los estudios lingüísticos. Por ello, las prácticas verbales y visuales en la sociedad deben ser explotadas para la interpretación objetiva de los discursos semióticos a un nivel icónico, léxico y mixto (Tsakona, 2009 b).

En tal sentido, desde el advenimiento del periodismo los dibujos animados, la caricatura y las viñetas han proporcionado impresiones sarcásticas concisas e inteligentes de los problemas de la sociedad a través de la mostración de situaciones específicas. Así surge la caricatura con el propósito de resaltar los problemas relacionados con las costumbres sociales, la economía, el orden público y las crisis internacionales. En la actualidad, estas caricaturas sociopolíticas aportan críticas y preguntas humorísticas al orden existente. Los prejuicios de los periódicos y los editores son las verdaderas cuestiones que a menudo se pasan por alto; sin embargo, están presente de forma sintética en las llamadas viñetas humorísticas que son caricaturas que proponen un discurso híbrido (visual-verbal) que juntos funcionan como manifestaciones explicativas, develadoras y motivadoras a través del código del humor (Iregui, 2021). Los caricaturistas utilizan la analogía, el etiquetado, el humor, la sátira y la exageración para expresar su opinión e ideología a los lectores. Así, las caricaturas se consideran una parte valiosa del periódico ya que éstas presentan los problemas existentes de manera diferente.

En consecuencia, la caricatura sociopolítica en forma de viñeta humorística se considera como un medio de representación gráfica de personajes públicos en la que se traslapa la opinión del editor. De este modo, los editores de los diarios son los portavoces de la postura ideológica de los periódicos, pues son ellos quienes filtran los contenidos. Por tanto, la ideología de los diarios queda develada en los usos reales del lenguaje para la producción de efectos específicos en los lectores. Así, de la gran cantidad de mensajes distintos que se expresan con signos en los diarios, se decantan ciertos rasgos semióticos esenciales que van configurando la categoría llamada «ideología». Y dentro de este medio de comunicación de masas, las viñetas humorísticas son uno de los modos iconoglósicos en que se sintetiza dicha ideología, las cuales no pueden examinarse de forma aislada de su contexto discursivo. (Eagleton, 1991). De aquí surge la importancia de efectuar el análisis semiótico de estas caricaturas sociopolíticas.

Las caricaturas en las viñetas generalmente contienen habilidades artísticas para retratar una imagen de interés público que va desde las costumbres sociales, las tradiciones, la historia, la economía hasta la política, la salud y el derecho. 
Estas viñetas humorísticas, por lo general, satirizan las normas existentes de la sociedad y las prácticas culturales (directa o indirectamente). La importancia de la sátira radica en ser un medio eficaz para enfrentar las locuras y los prejuicios humanos a través del discurso escrito y hablado, mientras que el arte se encarga, a su vez, de pintar o bosquejar dicha sátira con creatividad icónica. En las viñetas humorísticas se dan estos dos procedimientos de forma integral y significativa (Najafian, M. \& Dabaghi, 2011).

\section{Marco conceptual}

Si bien estas viñetas humorísticas brindan un escape a los largos discursos y sus explicaciones, es necesario comprenderlos a cabalidad a través de un análisis crítico de la discursividad. En tal sentido, el campo de la semiótica es muy importante porque permite resaltar el problema existente con las imágenes pictóricas. Puede destacar la cultura, los desórdenes culturales, los desórdenes políticos, el papel del lenguaje en la construcción de la conciencia social, el uso del lenguaje en lugares públicos, etc. Por ello, el estudio aquí abordado analiza la semiótica de las viñetas humorísticas de cuatro periódicos peruanos como Gestión, Perú 21, El Comercio, La República. Para la realización del estudio se ha integrado el modelo tridimensional del análisis crítico del discurso de Norman Fairclough y el modelo de análisis semiótico de Roland Barthes.

Los antecedentes de investigación que abordan el estudio de las caricaturas periodísticas realizan un estudio pragmático contextualizándolo con la situación sociocultural de la actualidad del momento como en el caso del estudio de Francia Martinez (2011) quien encuentra que las caricaturas de los periódicos denuncian y muestran los problemas sociales del momento mediante el discurso humorístico. Asimismo, los personajes caricaturizados, por lo general, están vinculados al ámbito político. Angélica Vásquez y Valentina Valencia (2018) quienes efectúan un análisis semántico y pragmático de las caricaturas periodísticas, aportando una manera de analizarlas con base a las categorías que propone Van Dijk para los análisis discursivos, en el que se considera a la caricatura como un discurso gráfico en el que se apoyan las editoriales de los medios de comunicación masivos. Y centrado en el impacto social de las caricaturas, la investigación de Viviana Castillo, María Rada y Diana Almeida (2019) se centra en la influencia social y psicológica que ejercen las caricaturas periodísticas en el público lector generando cambio de opinión.

$60 \quad$ Lengua y Sociedad. Revista de Lingüística Teórica y Aplicada 
Por otro lado, Anibal Yanes (2012) desde la perspectiva semiótica de Umberto Eco analiza el sistema de significación de las caricaturas así como el problema de su iconicidad. Otro estudio de carácter semiótico de las caricatura políticas es la investigación de Vasco Medina (2017) quien en su análisis sobre los motivos para creación de caricaturas políticas a partir de entrevistas a diversos caricaturistas encuentra el recurso satírico en el empleo del lenguaje icónico y verbal, el cual es metafórico y de exageración. Asimismo, se concluye que la sátira gira alrededor de la figura de los presidentes. La investigación de Carlos León (2020) permitió determinar la línea ideológica que muestran los diarios a través de sus viñetas periodísticas. Además, desde la perspectiva de Roland Barthes se concluye que los estudiantes son conscientes que la creación de opinión gráfica influye en la sociedad.

Finalmente, este estudio plantea cuatro preguntas de investigación, a saber: ¿Cuáles son las viñetas humorísticas que han surgido en tiempo de pandemia de la Covid-19 en los diarios de Lima Metropolitana a inicios del 2021?, ¿cómo presentaron los periódicos de Lima Metropolitana la emergencia sanitaria de la Covid-19 a través de las viñetas humorísticas en los primeros meses del 2021?, ¿cómo la semiótica de las viñetas humorísticas puede explicar la situación sociopolítica de la sociedad? y ¿de qué manera la semiótica de las viñetas humorísticas permite determinar la opinión e ideología de los editores de los diarios? De estas preguntas del estudio se derivan cuatro objetivos de investigación, a saber: 1) Registrar las viñetas humorísticas publicadas en tiempo de pandemia de la Covid-19 en los diarios de Lima Metropolitana a inicios del 2021; 2) Describir la manera cómo se presentó la emergencia sanitaria de la Covid-19 a través de las viñetas humorísticas en los diarios de Lima Metropolitana durante los primeros meses del 2021; 3) Determinar cómo a través del análisis semiótico de las viñetas humorísticas se puede explicar la situación sociopolítica de la sociedad; 4) Determinar la opinión e ideología de los editores de los diarios a través del análisis semiótico de las viñetas humorísticas en los diarios de Lima Metropolitana a inicios del 2021.

\section{Metodología}

Diseño. La investigación desarrolla una metodología de naturaleza cualitativa mediante un diseño de tipo análisis del discurso, debido a que se analiza desde el enfoque mixto lingüístico y semiótico un repertorio de viñetas humorísticas de los diarios de la prensa de Lima Metropolitana en tiempo de pandemia Sars CoV-2. Del mismo modo, el presente estudio es transversal-descriptivo ya que el 
análisis se efectúa sobre una muestra de viñetas publicadas durante el 2021 en la sociedad peruana a causa de la pandemia del coronavirus y del confinamiento (Loayza-Maturrano, 2020 b).

Participantes. En este estudio se considera como unidades de observación participantes a los diarios en versión impresa y digital (Perú 21, La República, El Comercio, Gestión). Asimismo, las viñetas humorísticas contenidas en cada uno de los diarios se consideran unidades de análisis ya que éstas fueron sometidas al proceso de análisis lingüístico-semiótico propuesto (Loayza-Maturrano, 2020 a).

Instrumento. Se empleó los diarios de circulación nacional en su versión impresa y digitalizada para recopilar las viñetas publicadas en periodo de pandemia, el instrumento que se empleó fue la Matriz Breve de Análisis Lingüístico-Semiótico (MBALs) adaptado del modelo tridimensional de análisis crítico del discurso de Norman Fairclough y el modelo del discurso semiótico de los medios de Roland Barthes que se estructura en dos procesos de análisis, a saber: $1^{\circ}$. Análisis lingüístico; $2^{\circ}$. Análisis semiótico. El análisis lingüístico tiene tres dimensiones o constructos, a saber: 1) Textual (nivel descriptivo); 2) práctica discursiva (nivel interpretativo) y 3) práctica social (nivel explicativo). Por su parte, el análisis semiótico tiene tres dimensiones o constructos, a saber: 1) Nivel denotativo de significancia; 2) nivel connotativo de significancia y 3 ) nivel semiológico.

Procedimiento. Los datos se recogieron a través de recortes de diarios impresos y capturas de imagen de las viñetas humorísticas de las distintas plataformas virtuales de los principales diarios de Lima Metropolitana en el transcurso de los primeros meses de la primera mitad del 2021. La Matriz Breve de Análisis Lingüístico-Semiótico (MBALs) fue aplicada caso por caso con el propósito de determinar las características linguosemióticas de las viñetas humorísticas publicadas en los principales diarios de Lima Metropolitana en época de pandemia.

\section{Resultados y Discusión}

La investigación se plantea en dos etapas: la primera etapa en la que se recopila la información gráfica y otra segunda de análisis de los casos. El resultado cumple con los cuatro objetivos principales del estudio: 1) registrar las viñetas humorísticas publicadas en tiempo de pandemia de la Covid-19 en los diarios de Lima Metropolitana a inicios del 2021; 2) describir la manera cómo se presentó la emergencia sanitaria de la Covid-19 a través de las viñetas humorísticas; 3 ) Determinar cómo a través del análisis semiótico de las viñetas humorísticas se puede explicar 
la situación sociopolítica de la sociedad y 4) Determinar la opinión e ideología de los editores de los diarios a través del análisis semiótico de las viñetas humorísticas.

\subsection{Recogida de datos}

La investigación permitió recopilar a través de las plataformas virtuales de los diarios un muestreo representativo del discurso iconosemiótico de la pandemia. Este registro evidencia rasgos simbólicos producto del contexto situacional que se atravesó en el segundo nivel de mayor incidencia del coronavirus SARs CoV-2 en el Perú. El muestreo iconográfico y fraseológico escudriña los nuevos sentidos y valores semióticos durante los meses de mayor impacto de la Covid-19.

Tabla 1. Registro de viñetas humorísticas de la pandemia Sars CoV-2

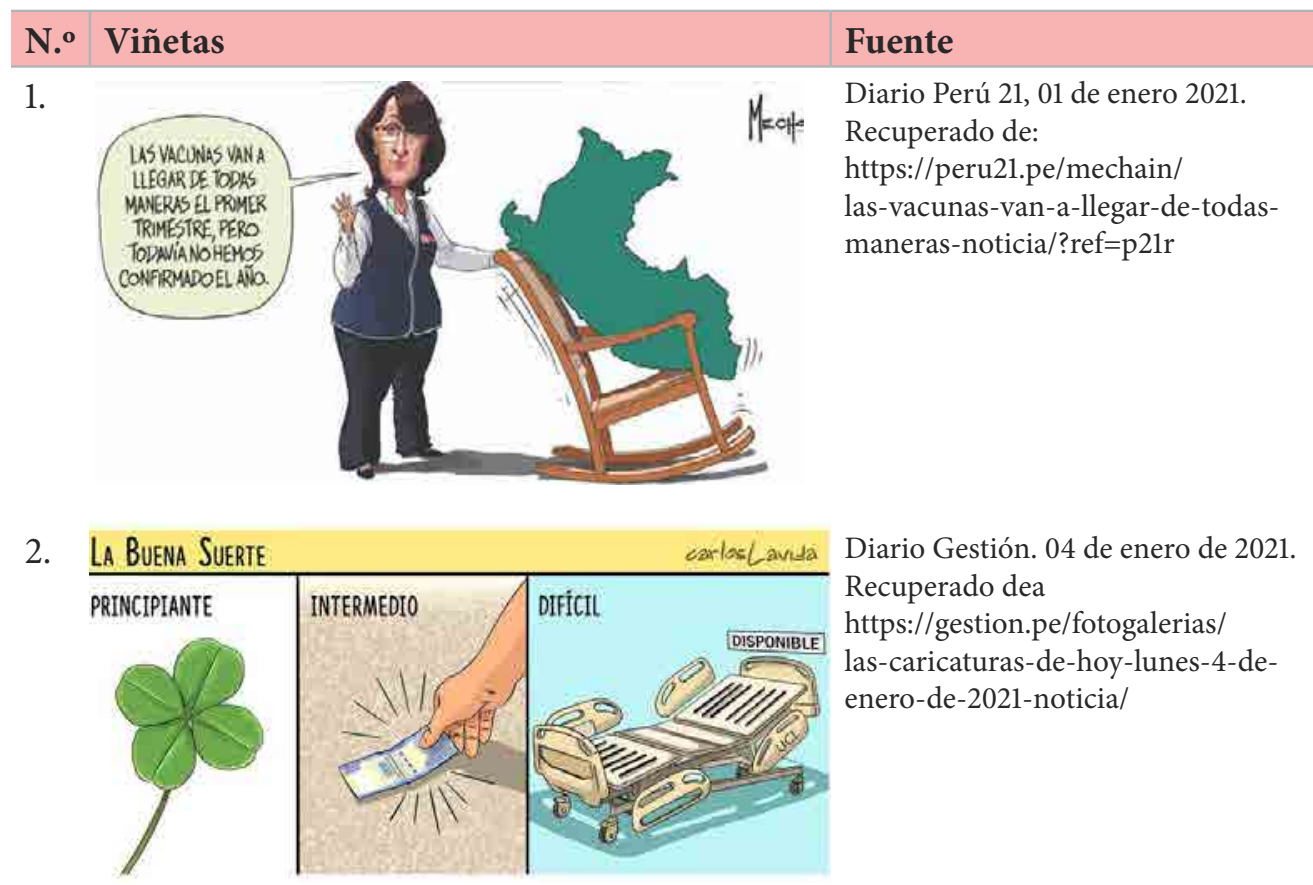


Análisis lingüístico-semiótico de las viñetas humorísticas sobre la covid-19

\section{N.o Viñetas}

3.

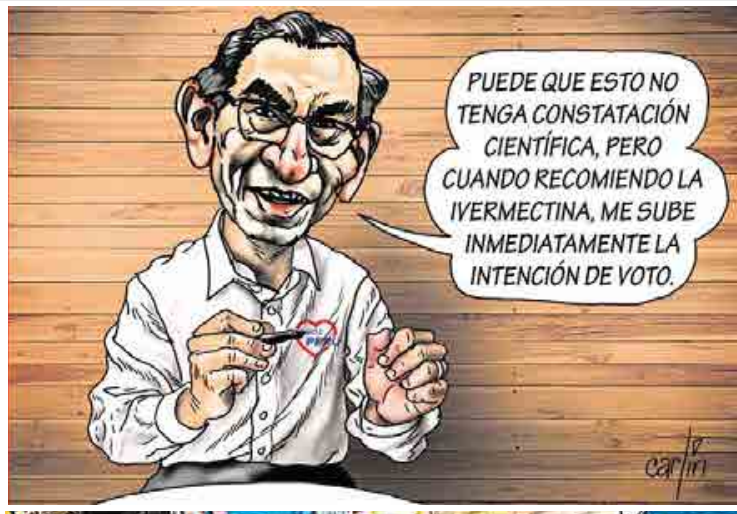

4. 3 NOLEIMPORTA GENERAR 4 CONLAS ACUSACIONES QUE YA TENGO, AGLOMERACIÓN Y CONTAGIOS? QUÉLE HACE UNARAYA MÁS AL TIGRE.

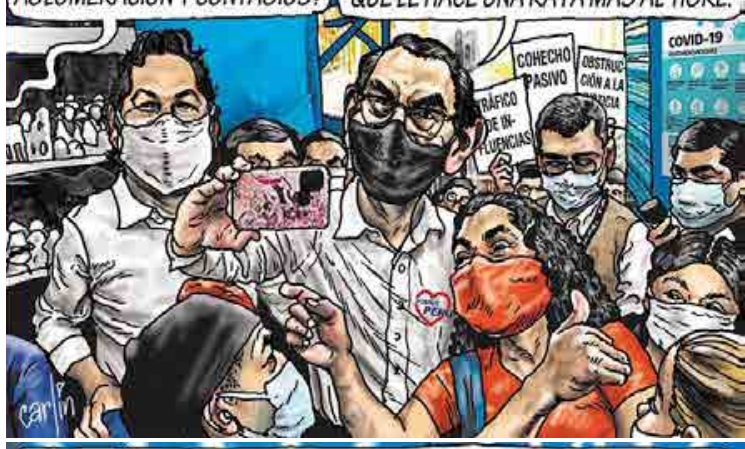

5. EL DESAFIO DE HOY, EN "ESTOES PANDEMIA": UN VIAJE DE IDA Y VUELTA ENUNA COMBIREPLETA, YLUEGO ALOJARSE EN UNA CASA SINAGUA POTABLENI REFRIGERADOR. NO OLVIDEN SU MASCARILLA, CUIDDENSE.

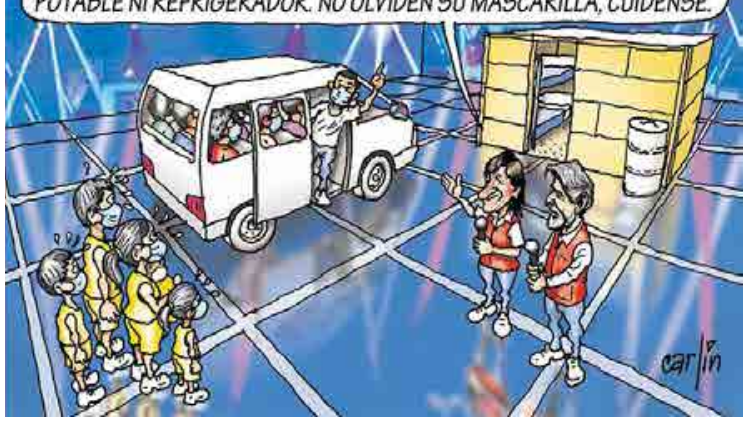

6.

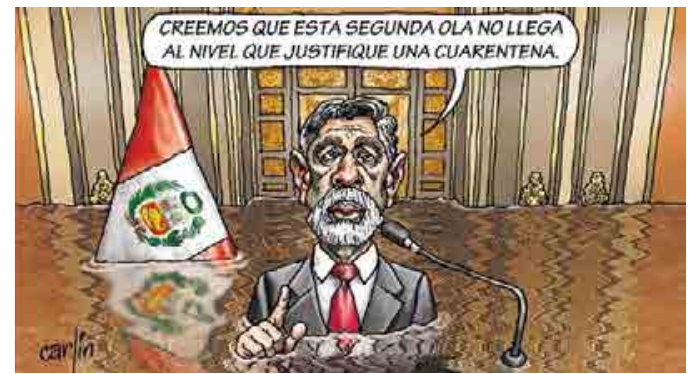

\section{Fuente}

La República, 12 de enero de 2021, Sociedad. Recuperado de: https://larepublica.pe/ carlincatura/2021/01/12/carlincaturade-hoy-martes-12-de-enero-de-2021/

La República, 15 de enero de 2021, Sociedad. Recuperado de: https://larepublica.pe/ carlincatura/2021/01/15/carlincaturade-hoy-viernes-15-enero-del-2021/
La República, 22 de enero de 2021, Sociedad. Recuperado de: https://larepublica.pe/ carlincatura/2021/01/22/carlincaturade-hoy-viernes-22-de-enero-de-2021
La República, 24 de enero de 2021, Sociedad. Recuperado de: https://larepublica.pe/ carlincatura/2021/01/24/carlincaturade-hoy-domingo-24-deenero-de-2021/ 


\section{N. ${ }^{\text {Viñetas }}$}

7.

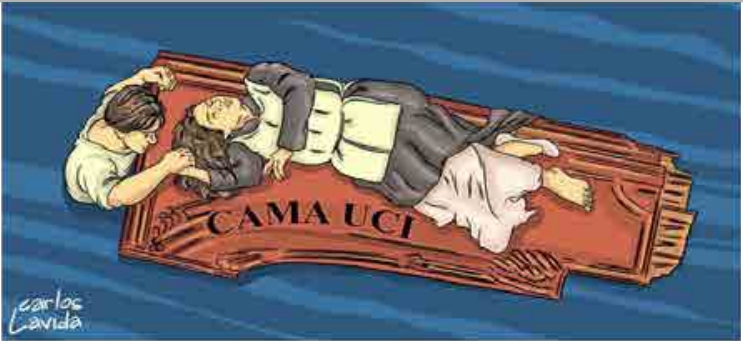

8.

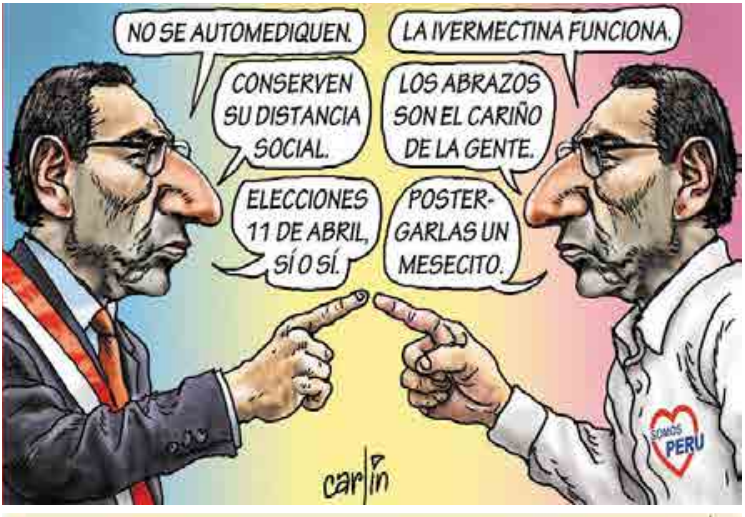

9.

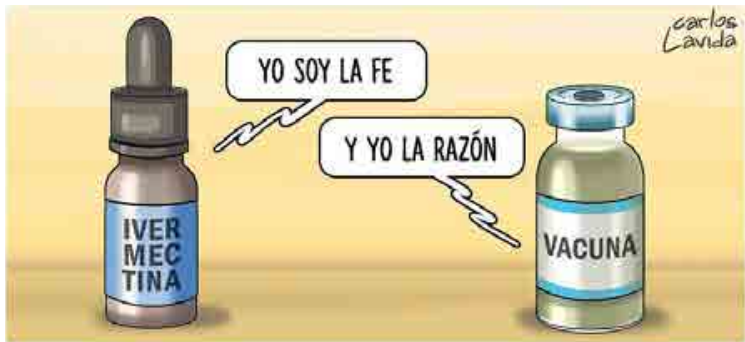

10.

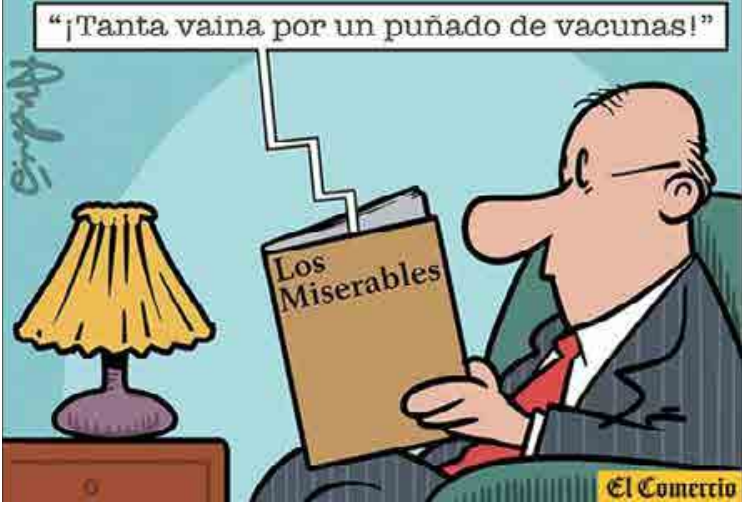

\section{Fuente}

Diario Gestión. 26 de enero de 2021.

Recuperado de:

https://gestion.pe/fotogalerias/

las-caricaturas-de-hoy-martes-26-deenero-de-2021-noticia/

La República, 31 de enero de 2021,

Sociedad. Recuperado de:

https://larepublica.pe/

carlincatura/2021/01/31/carlincatura-

de-hoy-31-de-enero-de-2021/

Diario Gestión. 08 de febrero de 2021. Recuperado de:

https://gestion.pe/fotogalerias/

las-caricaturas-de-hoy-lunes-8-defebrero-de-2021-noticia/

El Comercio, 09 de febrero de 2021.

Recuperado de:

https://elcomercio.pe/politica/

opinion/otra-vez-andres-noticia-47/ 
Análisis lingüístico-semiótico de las viñetas humorísticas sobre la covid-19

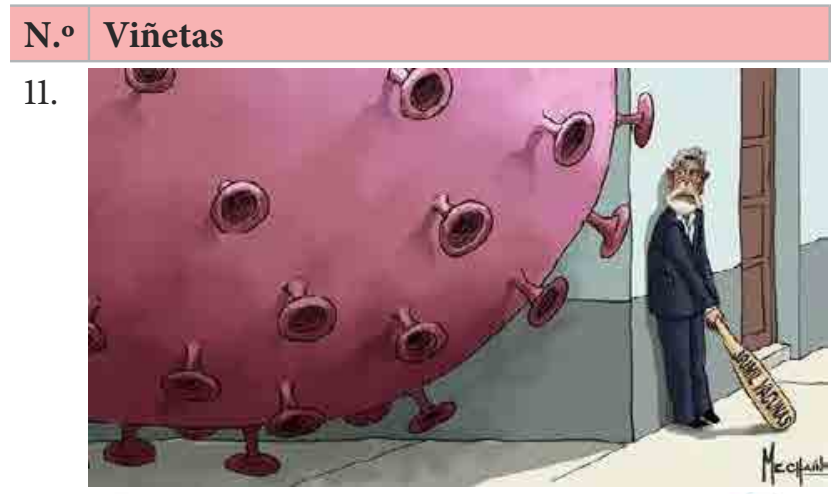

\section{Fuente}

Diario Perú 21, 11 de febrero 2021.

Recuperado de:

https://peru21.pe/mechain/

mechain-300-mil-vacunas-noticia/

12. सintoses

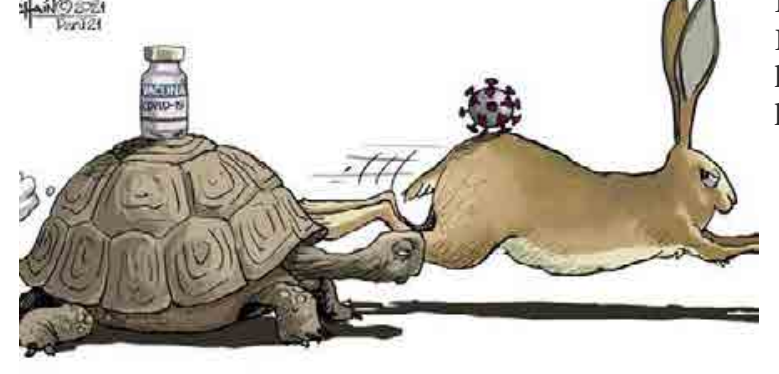

Diario Perú 21, 12 de febrero 2021.

Recuperado de:

https://peru21.pe/mechain/

la-tortuga-y-la-liebre-noticia/

13.

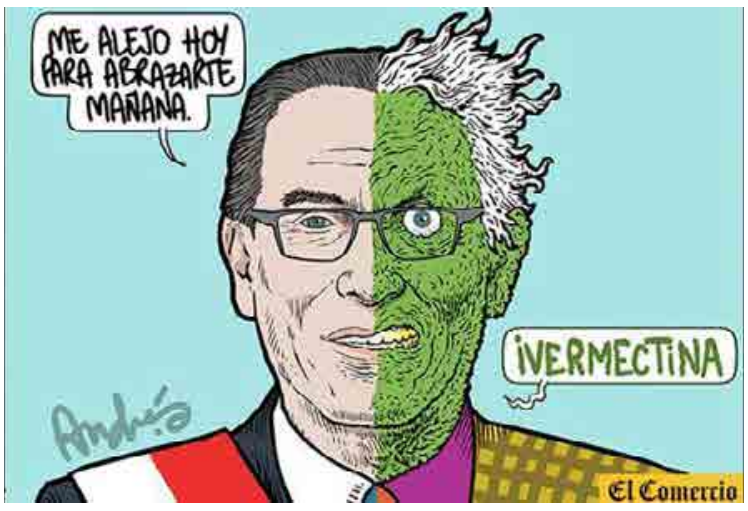

El Comercio, 12 de febrero de 2021

Recuperado de:

https://elcomercio.pe/politica/

opinion/otra-vez-andres-noticia-49/

14.

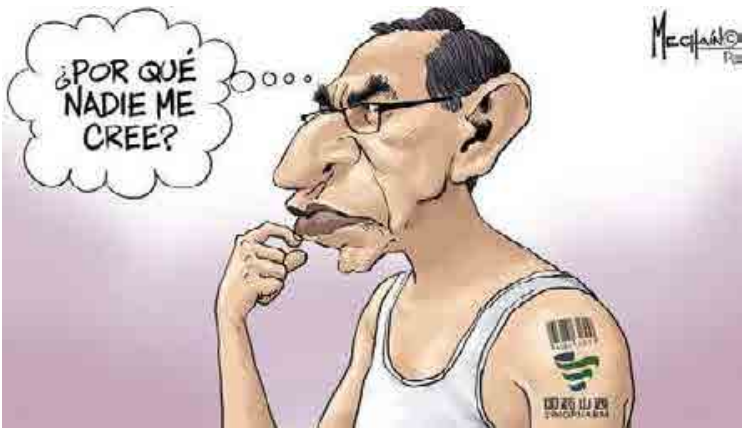

Recuperado de:

https://peru21.pe/mechain/

sinopharm-noticia/ 
Análisis lingüístico-semiótico de las viñetas humorísticas sobre la covid-19 Edward Faustino Loayza-Maturrano

N.o Viñetas

15.

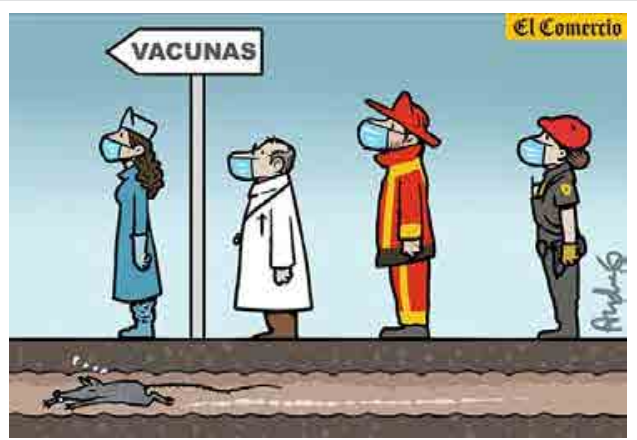

16.

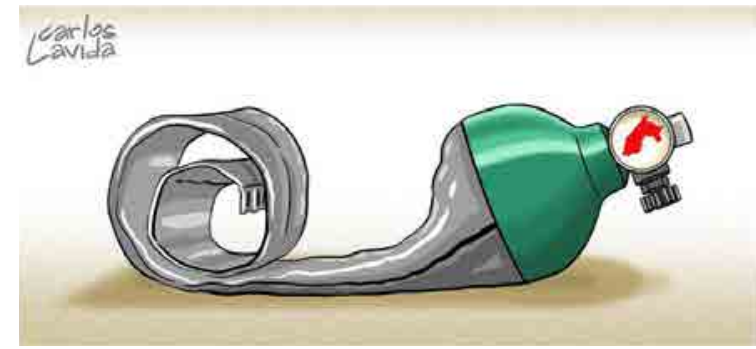

17.

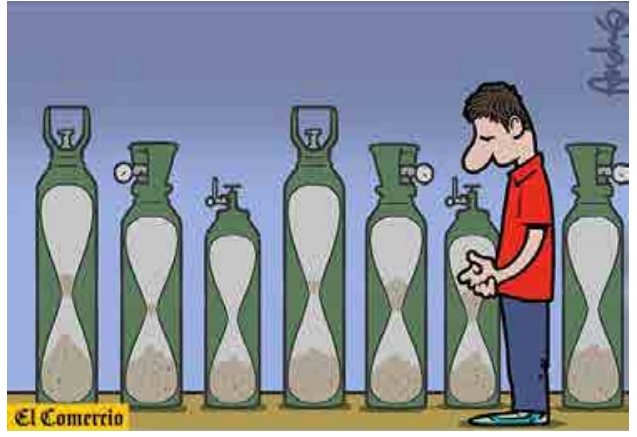

\section{Fuente}

El Comercio, 16 de febrero de 2021.

Recuperado de:

https://elcomercio.pe/politica/

opinion/otra-vez-andres-noticia-50/

Diario Gestión. 22 de febrero de 2021. Recuperado de: https://gestion.pe/ fotogalerias/las-caricaturas-de-hoylunes-22-de-febrero-de-2021-noticia/

El Comercio, 23 de febrero de 2021. Recuperado de: https://elcomercio.pe/politica/ opinion/otra-vez-andres-noticia-55/

Fuente: Elaboración propia

\subsection{Análisis de los casos}

El proceso de análisis lingüístico-semiótico se desarrolla en cinco pasos/etapas: 1) extraer del contexto situacional discursivo la(s) expresión(es) lingüística(s) enunciada en la viñeta. 2) Aplicar la matriz de análisis lingüístico; 3) Identificar los rasgos iconosemióticos y simbólicos de las viñetas; 4) Aplicar la matriz de análisis semiótico; 5) Síntesis interpretativa de la viñeta humorística. Este proceso metodológico permite efectuar el enfoque del análisis lingüístico-semiótico. A continuación se muestra en uno de los casos dicho proceso.

$1^{\circ}$. Extraer del contexto situacional discursivo la(s) expresión(es) lingüística(s) enunciada en la viñeta. 
Análisis lingüístico-semiótico de las viñetas humorísticas sobre la covid-19 Edward Faustino Loayza-Maturrano

La buena suerte... principiante... intermedio... difícil

(Fuente: Diario Gestión. 04 de enero de 2021)

$2^{\circ}$. Aplicar la matriz de análisis lingüístico MBAL (Grice, 1975; Fairclough, 1992).

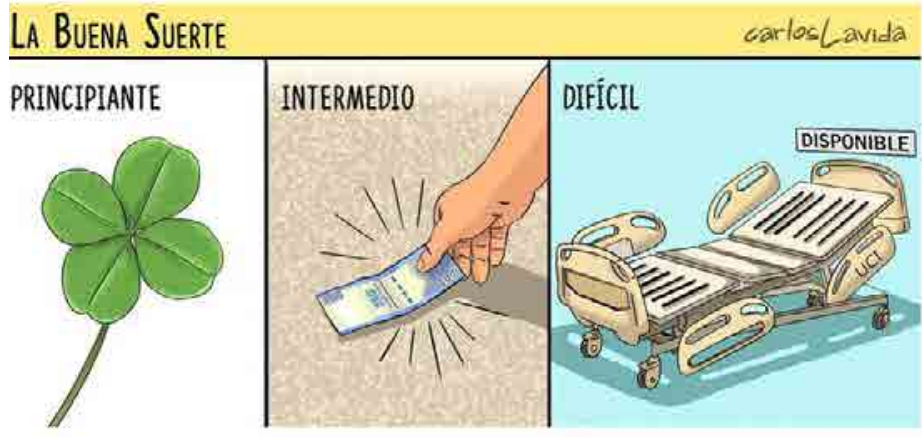

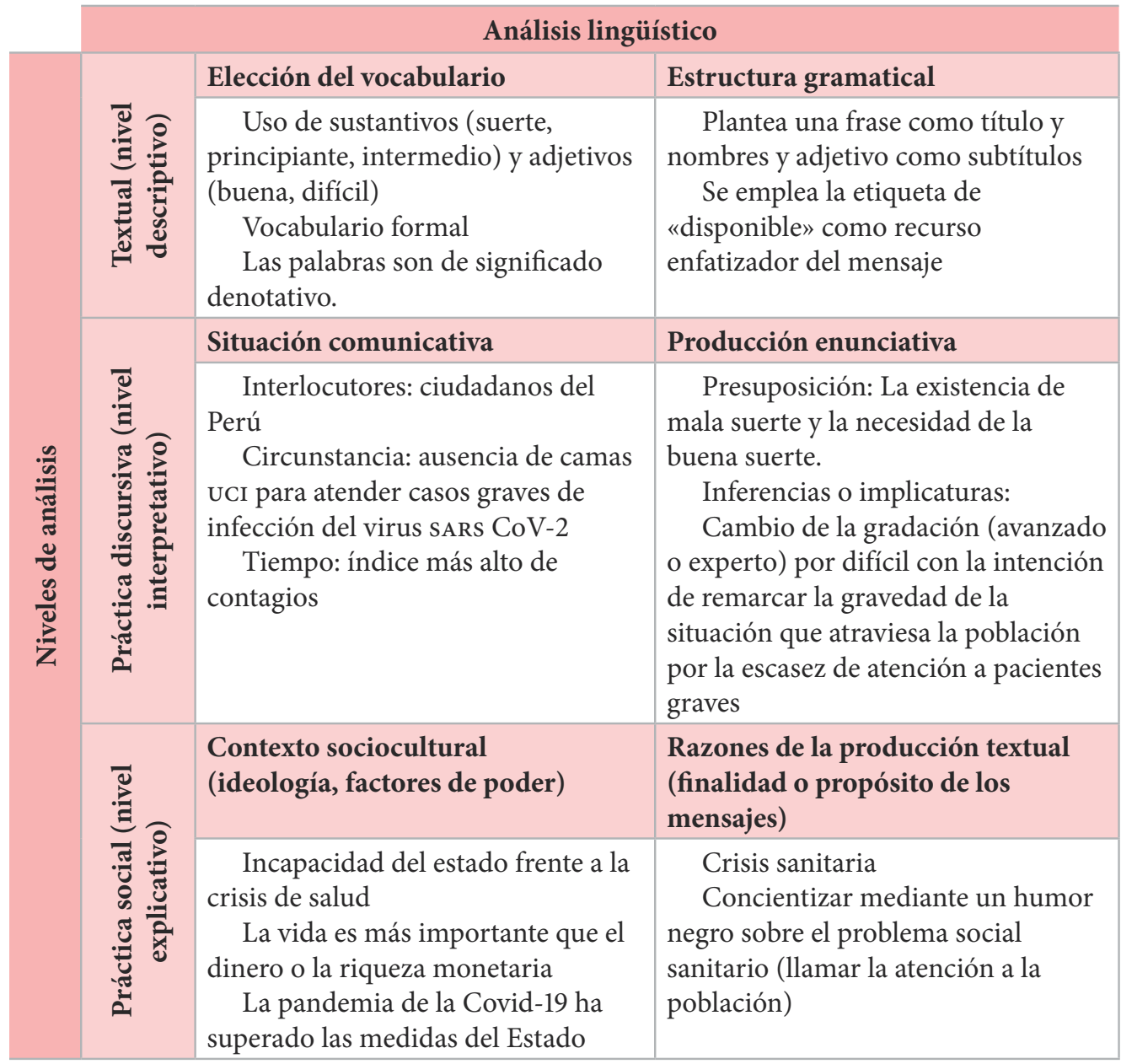


$3^{\circ}$. Identificar los rasgos iconosemióticos y simbólicos de las viñetas (procedimientos metafóricos, metonímicos e hiperbólicos) (Kövecses, 2017; Loayza Maturrano, 2021).

Rasgos iconosemióticos: 1) Imagen del trébol de cuatro hojas; 2) imagen de un billete encontrado en el piso; 3) imagen de una cama de cuidados intensivos (UCI) vacía.

Rasgos simbólicos:

1) metáforas gráficas:

a. el trébol de cuatro hojas simboliza la suerte (pronostica buena suerte)

b. Hallar un billete en el piso (consumación de la buena suerte)

c. la cama UCI disponible contextualizado en tiempo de pandemia de la Covid-19 representa la mejor de las suertes.

2) metonimia gráfica:

a. el billete de 100 soles encontrado representa riqueza financiera (relación elemento - conjunto)

b. la cama UCI representa obtener la atención en una unidad de cuidados intensivos para salvar la vida frente a enfermedad de la Covid-19 (relación parte-todo)

3) hipérbole gráfica:

a. No existe hipérbole porque las imágenes reflejan la realidad extrema de crisis sanitaria en que se encontraba el país.

$4^{\circ}$. Aplicar la matriz de análisis semiótico MBAL (Barthes, 2000). 
Análisis lingüístico-semiótico de las viñetas humorísticas sobre la covid-19 Edward Faustino Loayza-Maturrano

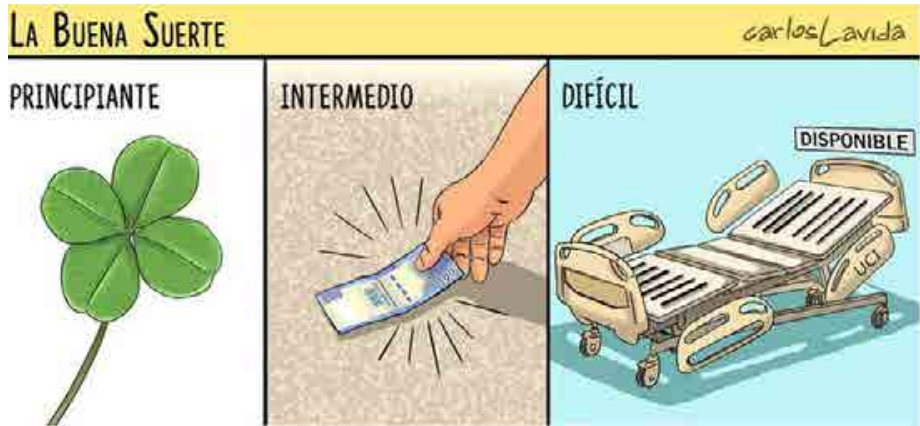

\begin{tabular}{|c|c|c|c|}
\hline & & Análisis semió & tico \\
\hline & & $\begin{array}{l}\text { Elección de los signos } \\
\text { (tipo(s) de signo-imagen) }\end{array}$ & $\begin{array}{l}\text { Significado visual o literal del } \\
\text { signo-imagen }\end{array}$ \\
\hline & 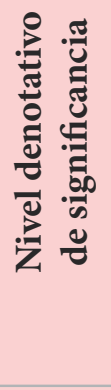 & $\begin{array}{l}\text { Signos empleados: } \\
\text { Símbolo: Trébol de cuatro hojas } \\
\text { Índice: El billete de } 100 \text { soles en el } \\
\text { piso } \\
\text { İ́no: La imagen de la cama clínica } \\
\text { vacía }\end{array}$ & $\begin{array}{l}\text { Signos empleados: } \\
\text { Símbolo: Trébol de cuatro hojas } \\
\text { simboliza la buena suerte } \\
\text { Índice: El billete de } 100 \text { soles } \\
\text { encontrado en el piso (causa) } \\
\text { indica la buena suerte (efecto) } \\
\text { Ícono: La cama clínica vacía } \\
\text { que representa a una cama en UCI } \\
\text { disponible }\end{array}$ \\
\hline 尝 & : & $\begin{array}{l}\text { Signo-imagen en la cultura } \\
\text { (tema y valor cultural) }\end{array}$ & $\begin{array}{l}\text { Interacción signo-imagen y } \\
\text { usuario (influencia emocional } \\
\text { del signo) }\end{array}$ \\
\hline 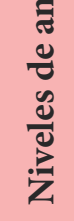 & 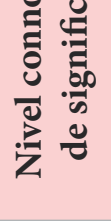 & $\begin{array}{l}\text { Tema: Crisis de la Covid-19 en el país. } \\
\text { Valores culturales: } \\
\text { La mayor importancia que tiene la salud } \\
\text { y la vida respecto del dinero y la suerte } \\
\text { Creencia en la suerte para el cambio }\end{array}$ & $\begin{array}{l}\text { El peligro, miedo y } \\
\text { preocupación que provoca en } \\
\text { los destinatarios por la situación } \\
\text { sanitaria del país. }\end{array}$ \\
\hline & & $\begin{array}{l}\text { Múltiples significados } \\
\text { (signo-imagen como lenguaje no } \\
\text { verbal abierto) }\end{array}$ & $\begin{array}{l}\text { Múltiples lecturas } \\
\text { (distintas interpretaciones del } \\
\text { signo-imagen según la cultura) }\end{array}$ \\
\hline & 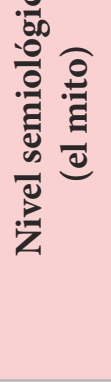 & $\begin{array}{l}\text { El país se encuentra en el índice } \\
\text { más alto de infectados y fallecimientos } \\
\text { por el Covid-19. } \\
\text { La sobrevaloración del dinero y } \\
\text { el consumismo cuando se remarca/ } \\
\text { resalta con líneas para indicar } \\
\text { luminosidad como si el billete brillara. } \\
\text { La antítesis al contraponer «mala } \\
\text { suerte» por «buena suerte» }\end{array}$ & $\begin{array}{l}\text { La ausencia de personas en la } \\
\text { viñeta significa la deshumanización } \\
\text { El vacío en la viñeta es } \\
\text { recurrente en los tres marcos lo } \\
\text { cual muestra ausencia de apoyo y } \\
\text { soledad para enfrentar la situación. }\end{array}$ \\
\hline
\end{tabular}


$5^{\circ}$ Síntesis interpretativa de la viñeta humorística (integración de los análisis).

El lenguaje iconoglósico de la viñeta «la buena suerte» evidencia la situación del contexto sociopolítico como es la incapacidad del Estado frente a la crisis de salud por la pandemia de la Covid-19, la cual ha superado las medidas adoptadas por el Estado y no se ha podido controlar. Asimismo, se denota la presencia de un humor negro desde el mismo título de la viñeta «la buena suerte» al satirizar la vida y la salud al considerarlas dentro de la lógica del juego (niveles) y al estar determinada por la suerte.

Por su parte, la semiótica de la viñeta denota índices y símbolos. El vacío en la viñeta es recurrente en los tres marcos lo cual es indicador de soledad y ausencia de apoyo frente a la crisis de la pandemia. Esto significa que estamos solos, cuidémonos nosotros mismos; el Estado no podrá salvarnos (mensaje oculto develado). El trébol es un símbolo histórico producto de las creencias pasadas y la tradición que se reactualiza para detentar la suerte. La ironía está presente al contraponer la situación crítica del sistema de salud, esto es, la «mala suerte» por la «buena suerte» como antítesis de la realidad. Esto es un grito o llamado: «queremos salud, queremos atención médica». Un rasgo ideológico de los editores o del diario queda evidenciada al resaltar el dinero (100 soles), queda claro la sobrevaloración que se otorga al dinero y la importancia que se da al consumismo (pues el dinero es para ser gastado). Asimismo, se evidencian procedimientos cognitivos vinculados al lenguaje como la metáfora (cama UCI en tiempo de pandemia representa la mayor de las suertes) y la metonimia (cama UCI por sala de cuidados intensivos). Esto demuestra la participación de procesos cognitivos en la manifestación del lenguaje icónico.

\subsection{Aporte al vacío del conocimiento}

La investigación considera el análisis crítico del discurso como una forma disciplinada de análisis de texto. En ese sentido, se considera el planteamiento de Fairclough quien ideó una forma de analizar sistemáticamente los datos disponibles con un enfoque científico. Este enfoque asume la idea de que el lenguaje también es un campo científico. Tres etapas de análisis proporcionan una idea del contexto sociopolítico de la producción de textos iconoglósicos, en este caso, del tipo viñeta humorística. Así, el texto es producto de procesos culturales que dan como resultado un gran discurso. Por su parte, el modelo de semiótica de 
Barthes proporciona una forma sistematizada de analizar el texto para comprenderlo mejor y obtener las verdaderas ideologías editoriales que se presentan en la semiótica.

En consecuencia, desde el enfoque lingüístico-semiótico de Fairclough y Barthes ha permitido develar las opiniones de los editores, la ideología de los diarios y la situación sociopolítica de la sociedad peruana a comienzos del 2021. Asimismo, a través del enfoque de la pragmalingüística de Grice y la lingüística cognitiva de Kövecses se logró explicitar los mensajes ocultos y los procedimientos cognitivos del lenguaje implicados en los significados de las viñetas humorísticas.

La investigación en cuestión analizó la semiótica de los periódicos de Lima Metropolitana en el momento de mayor nivel de incidencia de infectados por la pandemia del coronavirus en el Perú. Los diarios se centraron en la pandemia y de los peligros de la Covid-19. En el Perú se ha catalogado que en los meses de enero y febrero se produce la más severa y más alta incidencia de la Covid-19 desde la detección de los primeros casos en marzo del 2020. Los hospitales estaban llenos de personas infectadas con Covid-19 y los médicos también enfrentaban problemas de falta de infraestructura. Los hospitales carecían de camas UCI y los médicos se vieron obligados a trabajar en estas circunstancias. Toda esta devastadora situación fue retratada en la semiótica de las viñetas.

Los resultados del análisis de las viñetas muestran la recurrencia de personajes vinculados con la política del momento como la representación de la caricatura de la ministra de salud, del ex presidente y candidato al congreso el Señor Vizcarra, el presidente actual, el Señor Sagasti y otros personajes de la política (viñeta 1, 3, $4,6,8,11,13$ y 14). El lenguaje irónico y burlesco se muestra en expresiones como en el de la viñeta $\mathrm{N}^{\circ} 1$ cuando en el globo se expresa [«las vacunas van a llegar de todas manera el primer trimestre, pero todavía no hemos confirmado el año»], o en el caso de la viñeta $\mathrm{N}^{\circ} 6$ cuando en el globo se expresa: [Creemos que esta segunda ola no llega al nivel que justifique una cuarentena] y la imagen muestra el nivel alto del agua en que se ha inundado el despacho presidencial (Yanes, 2012).

El humor negro satírico se muestra en la viñeta 1 cuando el mapa del Perú está en una mecedora en movimiento, mecida por la ex ministra de salud. Igual situación se muestra en la viñeta $\mathrm{N}^{\circ} 7$ donde se encuentra una paciente de Covid-19 tomando oxígeno sobre un pedazo de tronco en las aguas de un río indicando con una etiqueta que está en una cama UCI. Esta viñeta ironiza sarcásticamente la falta de camas hospitalarias en unidades de cuidados intensivos, por haberse sobrepasado la capacidad de atención en los hospitales y clínicas de todo el

72 Lengua y Sociedad. Revista de Lingüística Teórica y Aplicada 
país. Del mismo modo, en las viñetas 16 y 17 se evidencia un crudo sarcasmo al presentar, en el primer caso, un balón de oxígeno de acero absorbido en un nivel extremo, como si fuese de aluminio, plástico o un cartucho de dentífrico y en cuyo medidor de nivel está el mapa del Perú en color rojo. En el segundo caso, al mostrar a una persona orando frente a una fila de balones de oxígeno que son al mismo tiempo relojes de arena, a los cuales se les acabó o está por acabárseles el tiempo. Este sarcasmo sobre la crisis del oxígeno evidencia un humor cáustico e hiriente dirigido hacia el lector, pues se ironiza sobre la muerte (Iregui, 2021).

Las caricaturas de las viñetas humorísticas también muestran la problemática sociopolítica que se atraviesa la sociedad; la carencia de vacunas (viñetas $1,10,11,12,15)$, el problema de la falta de oxígeno medicinal para el tratamiento de los infectados graves por Covid-19 (viñetas 7, 16, 17), la automedicación de la población por ivermectina (viñetas 3, 9, 13), la campaña electoral en tiempos de pandemia (viñetas 3, 4, 8), el doble discurso de los políticos (viñetas 8, 13, 14), la falta de conciencia de la población sobre el distanciamiento social (viñetas 4, 5), la escasez de camas UCI $(2,7)$. De otro lado, la opinión de los editores o la ideología de los diarios queda develada a través de los rasgos ideológicos que muestran cada una de las viñetas según el análisis semiótico realizado. Así, los diarios se muestran ideológicamente deshumanizados (viñetas 2, 7, 12, 13), personalizados o individualistas $(3,8,14,15,17)$, cosificantes o materialistas $(2,5,10,11,16)$, discriminadores $(4,5,10)$, politizados $(1,4,6,8,13,14)$, agnósticos (9) (Tsakona, 2009 a; Afzal et al., 2021).

Asimismo, el análisis lingüístico de las viñetas desde el enfoque de la pragmalingüística muestra que se transgreden las máximas conversacionales de modo (viñetas 3, 4, 5, 10, 12, 15), de calidad $(1,8,14)$, de cantidad (viñetas 5, 11, 16, 17), relevancia (viñetas $2,7,15)$ mediante el lenguaje verbal y el lenguaje icónico empleado. Las principales implicaturas que se evidencian son: La percepción de engaño de parte de la población respecto de la actuación de las autoridades de gobierno (viñeta $1,8,14$ ), crisis extrema de la sociedad peruana por falta de oxígeno (viñetas 16, 17), inestabilidad política (viñetas 4, 6, 8), anomia de la población (viñetas 4, 5), crisis sanitaria por falta de camas UCI (viñetas 2,7 ), prevalencia de los intereses políticos (viñetas $3,4,8$ ), escasez o poca disponibilidad de vacunas $(11,12,15)$, mala gestión gubernamental del problema de la pandemia (viñeta 10), la doble moral de los políticos (viñetas 8, 13, 14), la trascendencia de la fe en tiempo de pandemia (viñeta 9) (Grice, 1975, Loayza, 2013). 
En tanto, en el marco del enfoque de la lingüística cognitiva los resultados de la investigación lograron explicitar los mensajes ocultos y los procedimientos cognitivos del lenguaje implicados en los significados de las viñetas humorísticas. Así los principales rasgos iconosemióticos que se hallaron son: La imagen del mapa del Perú (viñetas 1, 16), la imagen del coronavirus (viñetas 11, 12), la imagen de una cama UCI (viñeta 2), la imagen de balón(es) de oxígeno (viñetas 16, 17), la imagen de animales (viñetas 12, 13), la imagen de la vacuna (viñetas 9, 12), la imagen del medicamento llamado ivermectina (viñeta 9), la imagen de personajes políticos (viñetas 1, 3, 4, 6, 8, 11, 13, 14) (Kress \& Leeuwen, 1996; Kövecses, 2017).

Por otro lado, los hallazgos de los principales rasgos simbólicos de las viñetas son: Metáforas gráficas como «el mapa del Perú sobre una mecedora» que representa el incumplimiento de promesas políticas respecto de la llegada de vacunas (viñeta 1). Otra metáfora gráfica es «un pedazo de tronco como si fuera cama UCI sobre las aguas de un río» que representa la crisis sanitaria y el déficit de camas UCI en los hospitales y clínicas en el país (viñeta 7). También, la imagen del «despacho presidencial inundado» que contradice las palabras del Presidente de la República, representa el nivel más alto de incidencia del impacto de la pandemia desde su aparición en el contexto peruano (la llamada «segunda ola») (viñeta 6). De la misma manera, en la viñeta 12 se observa una metáfora gráfica aludiendo en primer momento una referencia y analogía a la fábula de la «Tortuga y la Libre» en la que representa la lentitud en la gestión de las vacunas (la tortuga) y la rapidez del contagio por coronavirus (la libre); sin embargo, también representa la esperanza de que al final triunfará la tortuga, por tanto, en el futuro se vencerá al virus. Igualmente, «los balones de oxígeno con un reloj de arena dentro de ellos» que representa que el oxígeno que necesitan las personas con infección grave por la Covid-19 se está acabando y con ello se está acabando también la posibilidad de sobrevivir y superar la enfermedad (viñeta 17) (Kövecses, 2017; León, 2020).

Los procedimientos de metonimias gráficas halladas han sido variados. La metonimia de la «parte por el todo» queda representado gráficamente en los casos de «la cama UCI vacía», es decir, una cama hospitalaria que representa a «la unidad de cuidados intensivos» (viñeta 2). La metonimia del tipo «elemento por el conjunto» cuando se muestra la imagen de un virus coronavirus, una botella de vacuna, una botella de gotero del medicamento antiparasitario de la ivermectina y personas vestidas de indumentaria de enfermera, médico, bombero, policía (viñetas 9, 11, 12, 15). La metonimia por «contigüidad semántica» evidenciado mediante la imagen del «mapa del Perú» que refiere a la población peruana 
(viñeta 1). También la metonimia «característica adyacente del sujeto (animal) por el objeto» a través de la imagen de la libre y la tortuga por su características de rapidez y lentitud respectivamente (viñeta 12) (Kövecses, 2017).

Los principales procedimientos de hipérbole gráfica hallados son: el dibujo de un coronavirus gigante que representa una alta proporción de contagios y la insuficiencia de vacunas (trescientas mil) para la cantidad personas que supone la población peruana (más de treinta millones) (viñeta 11). Otra hipérbole gráfica está representado por el balón de oxígeno aplastado como si hubiese sido succionado pese a ser de acero, lo cual supone la situación crítica de falta de oxígeno medicinal en todo el país para atender los casos complicados por la infección del coronavirus (viñeta 16) (Grice, 1975; Loayza, 2011).

Por otro lado, la investigación realizada se corresponde con el estudio de las caricaturas periodísticas realizado por Francia Martinez (2011) y Carlos León (2020) ya que se demuestra que las viñetas denuncian y muestran los problemas sociales mediante un humor negro y satírico, así como expresar el plano ideológico del diario. Asimismo, se corrobora el estudio de Angélica Vásquez y Valentina Valencia (2018), la investigación de Vasco Medina (2017) y el estudio de Viviana Castillo, María Rada y Diana Almeida (2019) en el hecho del impacto social y psicológico en los lectores de los contenidos de dichas viñetas y del hecho de la caricaturización de personajes centrados en la política. Finalmente, el presente estudio explora un ámbito de análisis crítico del discurso centrado en la discursividad iconoglósica por lo que se abre una nueva línea de investigación interdisciplinaria de la lingüística aplicada a los mensajes de los mass media.

\section{Agradecimientos}

A los maestros del área de Lengua del Departamento de Ciencias Humanas de la Universidad Nacional Agraria La Molina por sus observaciones y revisiones para la construcción del presente manuscrito.

\section{Financiamiento}

La investigación se realizó con financiamiento propio.

\section{Conflicto de intereses}

Ninguno. 


\section{Conclusiones}

La investigación sostiene que el discurso de los periódicos tiene una carga ideológica que emplea un lenguaje colmado de significados múltiples y juega un papel importante en la construcción de la opinión de las masas. Por tanto, los medios de comunicación juegan un papel vital en la percepción pública. De este modo, el estudio es relevante pues se ha probado que la Matriz Breve de Análisis Lingüístico-Semiótico (MBALs) adaptada del modelo tridimensional de análisis crítico del discurso de Norman Fairclough y el modelo del discurso semiótico de los medios de Roland Barthes complementado con la pragmática de Grice y la lingüística cognitiva de Kövecses permite un abordaje integrado del análisis crítico del discurso.

La conclusión central se deriva del objetivo principal de la investigación, ya que se ha demostrado que el análisis semiótico de las viñetas humorísticas permite explicar la situación sociopolítica de la sociedad y la ideología de los diarios. Otra conclusión importante es que el estudio posibilitó registrar las viñetas humorísticas publicadas en tiempo de pandemia de la Covid-19 en los diarios de Lima Metropolitana a inicios del 2021 y también describir la manera cómo se presentó la emergencia sanitaria de la Covid-19 a través de estas caricaturas periodísticas.

Finalmente, se comprobó con este estudio la evidencia de procedimientos cognitivos del lenguaje como la metáfora conceptual, la metonimia conceptual y la hipérbole conceptual dentro del proceso lingüístico-semiótico y lingüístico-cognitivo que se produce en la discursividad iconoglósica de las viñetas humorísticas en los periódicos de Lima Metropolitana, por lo que se recomienda su aplicación como modelo de análisis para la interpretación de textos discontinuos.

\section{Referencias bibliográficas}

Afzal, N., Jabeen, I., Hameed, A. \& Sheikh, A. (2021). Use of persuasion and newspapers' representations of conflicts. Journal of Language and Linguistic Studies, 17(1), 398-411. https://doi.org/10.52462/jlls.24

Barthes, R. (2000). Mitologías, Madrid, Siglo XXI.

Castillo, V., Rada, M. \& Almeida, D. (2019). El uso de las caricaturas en la prensa nacional, como estrategia comunicacional. Revista Caribeña de Ciencias Sociales. https://www.eumed.net/rev/caribe/2019/05/caricaturas-prensa-nacional.html

76 Lengua y Sociedad. Revista de Lingüística Teórica y Aplicada 
Eagleton, T. (1991). Ideology: an introduction. London: Verso. https://archive. org/stream/TerryEagleton-IdeologyAnIntroduction/TerryEagleton-IdeologyAnIntroduction_djvu.txt

Fairclough, N. (1992). Discourse and Social Change. Cambridge: Polity Press.

Grice, H. (1975). Logic and conversation. En P. Cole \& J. Morgan (Ed.). Syntax and Semantics 3: Speech acts (pp. 41-58). Academic Press.

Iregui, P. (2021). El humor gráfico en tiempos de campaña: estudio de las viñetas políticas de Matador por medio del análisis crítico del discurso multimodal. [Tesis de grado]. Pontificia Universidad Javeriana. http://hdl.handle.net/10554/53492

Kövecses, Z. (2017). Levels of metaphor. Cognitive linguistics, 28(2), 321-347. https://doi.org/10.1515/cog-2016-0052

Kress, G. \& van Leeuwen, T. (1996). Reading Images, the Grammar of Visual Design. Routledge.

León, C. (2020). Análisis semiótico de la columna de caricaturas del Diario Universo, durante el paro nacional del 2019 y su influencia en la opinión pública de los estudiantes del octavo semestre de Comunicación Social de la Universidad Técnica de Babahoyo. [Tesis de grado]. Universidad Técnica de Babahoyo. http://dspace. utb.edu.ec/handle/4900o/7449

Loayza Maturrano, E. (2011). Análisis pragmático del código oral del transporte público urbano ('lenguaje combi ') en Lima Metropolitana. Lengua y Sociedad, 11(1), 91-100. http://revista.letras.unmsm.edu.pe/index.php/ls/ article/view/415

Loayza Maturrano, E. (2013). Análisis pragmático de la jerga técnica de los estudiantes de Unalm. Lengua y Sociedad, 13(1), 155-167. http://revista.letras. unmsm.edu.pe/index.php/ls/article/view/445

Loayza Maturrano, E. (2020a). Análisis semiótico del lexicón de la comida peruana amazónica. ConCiencia EPG, 5(2), 90-109. https://doi.org/10.32654/ CONCIENCIAEPG. 5-2.6

Loayza Maturrano, E. (2020b). La investigación cualitativa en Ciencias Humanas y Educación. Criterios para elaborar artículos científicos. Educare et Comunicare, 8 (2), 56-66. https://doi.org/10.35383/educare.v8i2.536

Loayza Maturrano, E. (2021). Análisis lingüístico-cognitivo del discurso desde la gramática cognitiva. PURIQ, 3(2), 466-487. https://doi.org/10.37073/ puriq.3.2.176 
Análisis lingüístico-semiótico de las viñetas humorísticas sobre la covid-19

Martínez-Valencia, F. (2011). La caricatura editorial colombiana. Una perspectiva semántica y pragmática. Revista de Filología y Lingüística. Universidad de Costa Rica, 213-227. https://doi.org/10.15517/RFL.V37I1.2355

Medina, V. (2017). Análisis de los componentes semánticos y pragmáticos de la caricatura política panameña. [Tesis de Maestría]. Universidad de Panamá. http:// up-rid.up.ac.pa/id/eprint/1496

Najafian, M. \& Dabaghi, A. (2011). Hidden language of advertising: A semiotic approach. In Proceedings of the International Conference: Doing Research in Applied Linguistics, 20-26. https://arts.kmutt.ac.th/dral/PDF\%20CD\%200n\%20 Web/20-26_Hidden_Language_of_Advertising.pdf

Pierce,C.(1974).Lacienciadelasemiótica. Nuevavisión.http://107.152.36.151:8080/ jspui/bitstream/123456789/152/1/PEIRCE-CH.-S.-La-Ciencia-de-LaSemi\%c3\%b3tica.pdf

Price C. \& Devlin J. (2003). The myth of the visual word form area. Neuroimage, 19(3), 473-81. https://doi.org/10.1016/s1053-8119(03)ooo84-3

Saussure, F. (1916). Cours de linguistique générale. Publié par Charles Bally et Albert Sechehaye, avec la collaboration de Albert Riedlinger, Lausanne/París.

Saussure, F. (1971). Curso de Lingüística General. Traducción española de Amado Alonso, Buenos Aires, Losada. http://www.semiologia-cbc-distefano.com.ar/ bibliografia/unidad-1/Saussure-1984-Curso-de-Linguistica-general.pdf

Tsakona, V. (2009 a). Language and image interaction in cartoons: Towards a multimodal theory of humor. Journal of Pragmatics, 41(6), 1171-1188. https:// doi.org/10.1016/j.pragma.2008.12.003

Tsakona, V. (2009 b). Humor and image politics in parliamentary discourse: a Greek case study. Text \& Talk, 29(2), 219-237. https://doi.org/10.1515/ TEXT.2009.010

Vásquez, A. \& Valencia, V. (2018). Análisis de la caricatura periodística referente al paro nacional de maestros de mayo de 2017. [Tesis de grado]. Universidad de Manizales. https://ridum.umanizales.edu.co/xmlui/handle/20.500.12746/3530

Yanes, A. (2012). Un acercamiento a la caricatura: algunas consideraciones semiósicas. Visitas al Patio, (6), 131-150. https://doi. org/10.32997/2027-0585-vol.o-num.6-2012-1671

78 Lengua y Sociedad. Revista de Lingüística Teórica y Aplicada 


\section{Trayectoria académica del autor}

Edward Faustino Loayza Maturrano es magíster en Didáctica de la Comunicación, profesor universitario en el área de Lengua del Departamento de Ciencias Humanas y Educación de la Universidad Nacional Agraria La Molina. Educador e investigador en el campo de la lingüística y educación. Ha publicado investigaciones en diversas revistas indizadas Sus áreas de interés son la lingüística, la educación y la literatura. 